\title{
Archaerhodopsin Voltage Imaging: Synaptic Calcium and BK Channels Stabilize Action Potential Repolarization at the Drosophila Neuromuscular Junction
}

\author{
Kevin J. Ford and Graeme W. Davis \\ Department of Biochemistry and Biophysics, University of California, San Francisco, San Francisco, California 94158
}

\begin{abstract}
The strength and dynamics of synaptic transmission are determined, in part, by the presynaptic action potential (AP) waveform at the nerve terminal. The ion channels that shape the synaptic AP waveform remain essentially unknown for all but a few large synapses amenable to electrophysiological interrogation. The Drosophila neuromuscular junction (NMJ) is a powerful system for studying synaptic biology, but it is not amenable to presynaptic electrophysiology. Here, we demonstrate that Archaerhodopsin can be used to quantitatively image AP waveforms at the Drosophila NMJ without disrupting baseline synaptic transmission or neuromuscular development. It is established that Shaker mutations cause a dramatic increase in neurotransmitter release, suggesting that Shaker is predominantly responsible for AP repolarization. Here we demonstrate that this effect is caused by a concomitant loss of both Shaker and slowpoke (slo) channel activity because of the low extracellular calcium concentrations $(0.2-0.5 \mathrm{~mm})$ used typically to assess synaptic transmission in Shaker. In contrast, at physiological extracellular calcium (1.5 mM), the role of Shaker during AP repolarization is limited. We then provide evidence that calcium influx through synaptic $\mathrm{CaV} 2.1$ channels and subsequent recruitment of Slo channel activity is important, in concert with Shaker, to ensure proper AP repolarization. Finally, we show that Slo assumes a dominant repolarizing role during repetitive nerve stimulation. During repetitive stimulation, Slo effectively compensates for Shaker channel inactivation, stabilizing AP repolarization and limiting neurotransmitter release. Thus, we have defined an essential role for Slo channels during synaptic AP repolarization and have revised our understanding of Shaker channels at this model synapse.
\end{abstract}

Key words: BK channel; Kv1 channel; NMJ; presynaptic; short term plasticity; voltage imaging

\section{Introduction}

Three families of potassium channels have been implicated in action potential (AP) repolarization at glutamatergic synapses: Kv1, Kv3, and BK channels. Kv1 channels were first shown to regulate neurotransmitter release at the neuromuscular junction (NMJ) in Drosophila (Jan et al., 1977). Kv1 channels also drive AP repolarization at the synapses of layer 5 pyramidal cells (Foust et al., 2011) and onto hippocampal pyramidal neurons (Buckle and Haas, 1982; Hu et al., 2001). At the fast-spiking calyx of Held, fast activating Kv3.1 channels provide the dominant repolarizing drive (Dodson et al., 2003; Nakamura and Takahashi, 2007). At mossy fiber boutons (Alle et al., 2011) and cerebellar stellate cells (Rowan et al., 2014), a combination of $\mathrm{Kv} 3$ and $\mathrm{Kv} 1$ channels dictate the shape of the AP.

In contrast, the function of BK channels, which have been observed to concentrate at or near the active zone and sites of

\footnotetext{
Received May 30, 2014; revised Aug. 23, 2014; accepted Sept. 10, 2014.

Author contributions: K.J.F. and G.W.D. designed research; K.J.F. performed research; K.J.F. analyzed data; K.J.F. and G.W.D. wrote the paper.

This work was supported by National Institutes of Health Grants SN39313 (G.W.D.) and F32 NS081997 (K.J.F.). We thank Ozgur Genc and Mike Gavino for comments on this manuscript and Martin Muller for technical assistance. We thank Amy Tong for help generating Arch-GFP transgenic flies.

The authors declare no competing financial interests.

Correspondence should be addressed to Graeme Davis at the above address. E-mail: Graeme.Davis@ucsf.edu. DOI:10.1523/JNEUROSCI.2203-14.2014

Copyright $\odot 2014$ the authors $\quad 0270-6474 / 14 / 3414517-09 \$ 15.00 / 0$
}

presynaptic calcium influx (Robitaille and Charlton, 1992; Issa and Hudspeth, 1994; Pattillo et al., 2001; Sun et al., 2004), remains less clear (Knaus et al., 1996; Hu et al., 2001; Pattillo et al., 2001; Misonou et al., 2006). Importantly, the calcium and voltage-dependent activation of BK channels is sufficiently rapid to have an effect on AP repolarization (Pattillo et al., 2001; Sun et al., 2004). However, the loss or inhibition of BK channels does not uniformly enhance neurotransmitter release. Inhibition of BK channels enhances release at hippocampal CA3-CA3 synapses (Raffaelli et al., 2004) but is without effect at other synapses (Hu et al., 2001; Alle et al., 2011), including the Drosophila NMJ (Lee et al., 2008).

The Drosophila NMJ is a powerful genetic model system for synaptic biology. This system benefits from a wide array of genetic reagents, the ability to perform quantal analysis (Jan and Jan, 1976), a stereotyped synaptic architecture, and paradigms for studying synaptic growth, degeneration, and homeostatic plasticity (Collins and DiAntonio, 2007; Davis, 2013). However, because type 1 glutamatergic boutons are surrounded by postsynaptic muscle, it has not been possible to directly assay the presynaptic AP waveform (but see Martínez-Padrón and Ferrús, 1997). Thus, it remains unclear which channels shape the synaptic AP. For example, mutations in the Shaker (Kv1) gene greatly enhance release in experimental recording conditions of low extracellular calcium (Jan et al., 1977; Stern and Ganetzky, 1989; 
Mallart et al., 1991; Ueda and Wu, 2006; Lee et al., 2008). In contrast, mutations that disrupt the slowpoke (slo) gene (encoding a BK channel ortholog) have little effect on release (Warbington et al., 1996). Although a synergistic enhancement of synaptic transmission is observed after removal of both the slo and Shaker genes (Gho and Ganetzky, 1992; Warbington et al., 1996; Lee et al., 2008, 2014), the basis for this effect remains unknown (but see Lee et al., 2008). Here, we use transgenically encoded, voltage-sensitive Archaerhodopsin (Arch; Kralj et al., 2012; Maclaurin et al., 2013) to define the role of presynaptic calcium, Kv1, and BK channels during the presynaptic AP waveform and subsequent neurotransmission at the Drosophila NMJ.

\section{Materials and Methods}

Generation of UAS-Arch. A plasmid containing Archaerhodopsin3 with a C-terminal GFP tag was obtained (Addgene plasmid 22217). The coding sequence for Arch was cloned into the PUAST destination vector to generate UASArch. This construct was confirmed by sequencing. Transgenic flies were generated using standard injection methods by BestGene. Stocks containing UAS-Arch insertions on chromosomes 2 and 3 were used for experiments. All imaging and electrophysiology experiments on Arch-expressing flies were performed using two copies of UAS-Arch (two on chromosome II, or one on II and one on III) and one copy of the motor neuron driver OK371-GAL4.

Flies stocks and genetics. $\mathrm{Sh}^{14}$, slo $^{1}, \mathrm{cac}^{\mathrm{S}}$, and OK371-GAL4 were used in experiments. Drosophila stocks were maintained at $22^{\circ} \mathrm{C}$ on normal food. For Arch imaging experiments, crosses were set up and allowed to lay for 2-3 d on food containing $1 \mathrm{~mm}$ all-trans retinal (ATR) food. Crosses containing ATR were wrapped in foil and kept at $25^{\circ} \mathrm{C}$. For experiments involving $\mathrm{Sh}^{14}$ and $c a c^{S}$, male hemizygous larvae were used. Otherwise, both male and female larvae were used.

Electrophysiology. Sharp-electrode recordings were made from muscle 6 in abdominal segments 2 and 3 of third-instar larvae using an Axopatch 200B amplifier (Molecular Devices), as described previously (Frank et al., 2006). The extracellular hemolymph-like-3 saline contained the following (in mM): $70 \mathrm{NaCl}, 5 \mathrm{KCl}, 10 \mathrm{MgCl}_{2}, 10 \mathrm{NaHCO}_{3}, 115$ sucrose, 4.2 trehalose, 5 HEPES, and $\mathrm{CaCl}_{2}$ at the concentration specified in the text or figure legends. Although changes in $\mathrm{CaCl}_{2}$ concentration were not compensated by adjusting $\mathrm{MgCl}_{2}$, the concentrations of extracellular divalents changed by at most $15 \%$ across experiments. Note that the effects of calcium on the AP waveform were explored not only by altering extracellular calcium but also by pharmacological and genetic manipulation of the calcium channel, ruling out potentially confounding effects of altered extracellular divalents. Extracellular bouton recordings were performed as described previously (Davis and Goodman, 1998).

Arch imaging. Confocal spot imaging was made from type $1 \mathrm{~b}$ boutons on muscle $6 / 7$ of abdominal segments $2-4$ of third-instar larvae using a confocal laser-scanning microscope (Ultima; Prairie Technologies). Excitation light ( $643 \mathrm{~nm}, 4 \mathrm{~mW}$ at the back of objective) from an air-cooled
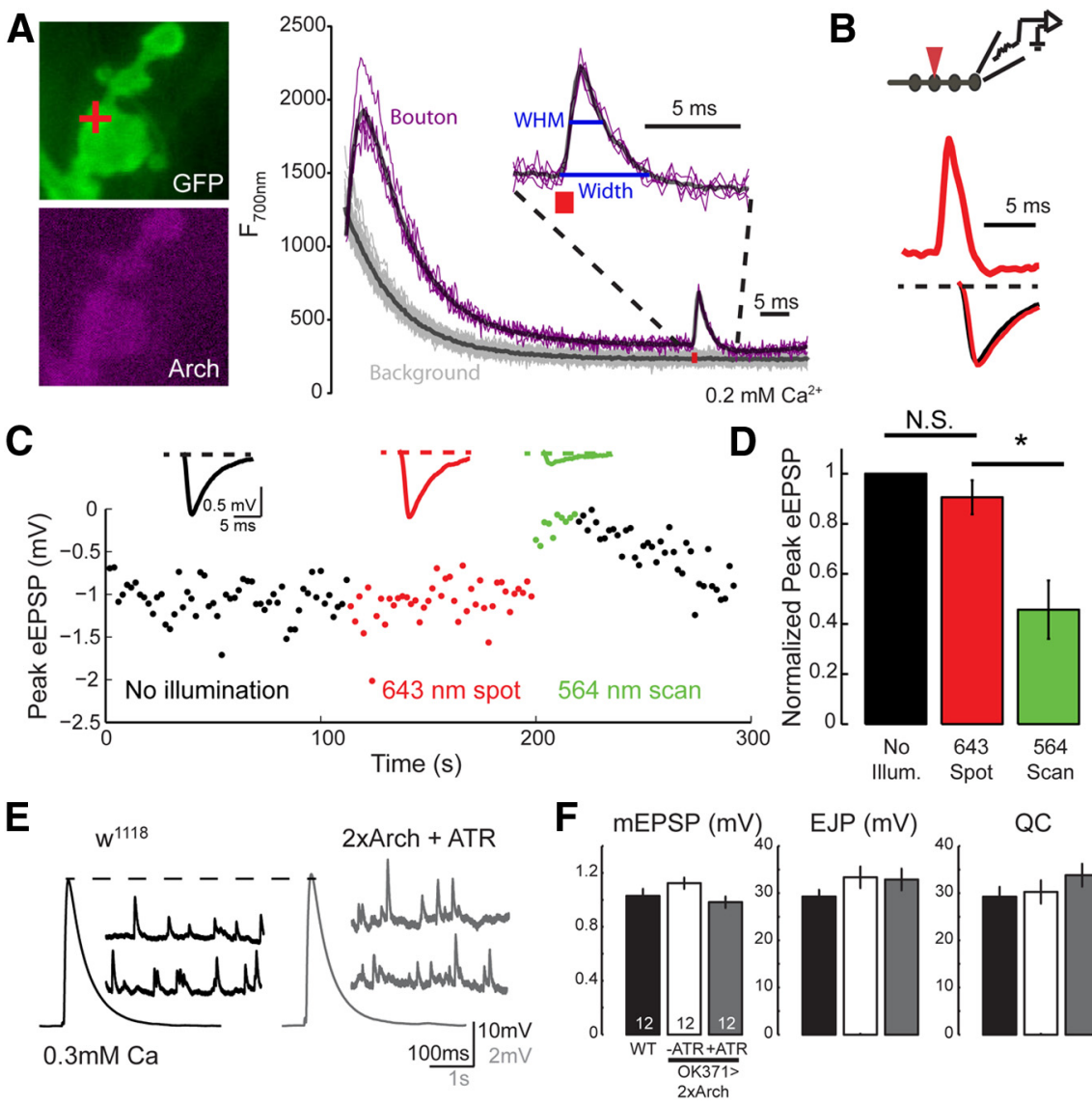

QC

Figure 1. Arch measures evoked APs at the NMJ without altering release. $\boldsymbol{A}$, Left, Fluorescence images of GFP and Arch fluorescence expressed presynaptically at the NMJ. Red crosshairs indicate location of point scan. Right, Spot confocal measurement of Arch fluorescence over time with stimulus-evoked AP highlighted and enlarged. Magenta traces represent five individual muscle. Black traces are the average of 50 scans. Red bar indicates the time of nerve stimulation during optical scan. Dotted lines indicate the expanded region, including AP waveform. Blue horizontal bars indicate the width and WHM measurements. $\boldsymbol{B}$, Top, bouton (distal). Red arrowhead indicates spot confocal illumination site at a proximal bouton. Bottom, Arch fluorescence AP voltage). $\boldsymbol{C}$, The amplitude of extracellularly recorded postsynaptic potentials are shown over time. A continuous recording is

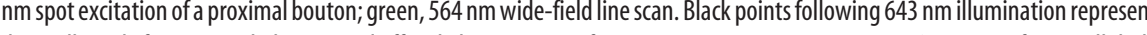
列 in larvae expressing two copies of UAS Arch raised on food containing ATR. $F$, Summary of average mEPSPs, evoked EJPs, and quantal content (QC) for WT larvae expressing two copies of Arch with $(+)$ and without $(-)$ ATR. $n=12$ for each condition. There is no statistically significant difference between conditions.

solid-state laser was focused onto the specimen using a $60 \times$ objective (1.0 numerical aperture; Olympus). The emission path consisted of a quad band 405, 488, 515, $643 \mathrm{~nm}$ dichroic, $500 \mathrm{~nm}$ long-pass filter, 600 $\mathrm{nm}$ dichroic, and 700/75 and 525/40 nm bandpass emission filters for Arch and GFP emissions, respectively. Arch emission was detected with a gallium arsenide phosphide-based photocathode photomultiplier tube (PMT; Hamamatsu), and GFP emission was detected by a second PMT. Spot imaging from the edges of single boutons was performed using continuous spot illumination with $250 \mu$ s binning of photons on the PMT to yield a sampling frequency of $4 \mathrm{kHz}$. The diffraction-limited spot had a central disk diameter of $\sim 780 \mathrm{~nm}$ at the focal plane. A $1 \mathrm{~ms}$ stimulation of the nerve fiber was used to evoke APs after $60 \mathrm{~ms}$ of baseline image acquisition. Thirty to 50 events were collected for each bouton at an interstimulus rate of $0.5 \mathrm{~Hz}$ for single APs and an intertrain interval of $0.1 \mathrm{~Hz}$ for trains of five stimuli. One to five boutons per synapse were imaged. For experiments using $1.5 \mathrm{~mm}$ calcium, $10 \mu \mathrm{M}$ 

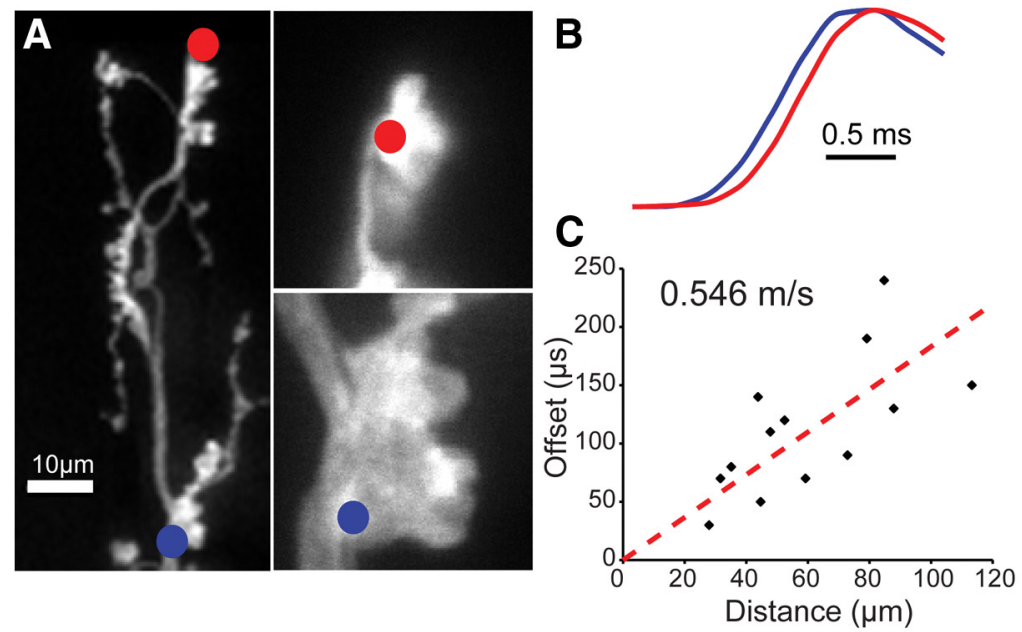

D

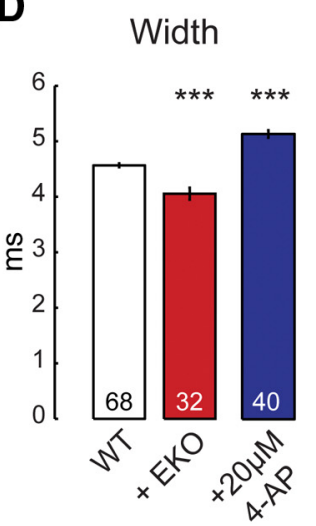

E

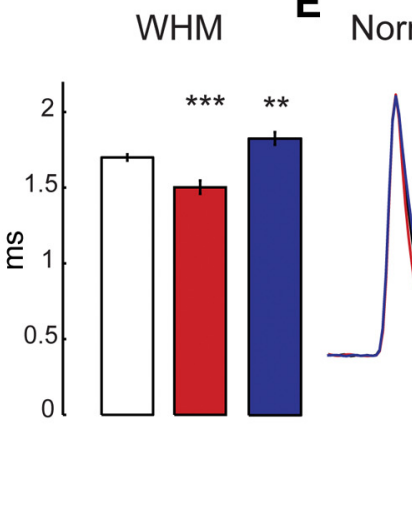

WT

EKO

$20 \mu \mathrm{M} 4-\mathrm{AP}$

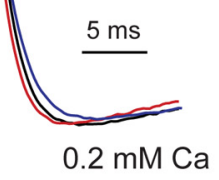

Figure 2. Arch imaging can resolve AP propagation and changes in AP width. A, GFP fluorescence image of the NMJ expressing UAS-Arch-GFP ( 2 copies). Spot measurements were made at proximal (blue) and distal (red) sites as indicated. Expanded image of the boutons are shown on the right $(4 \times)$. $\boldsymbol{B}$, Arch voltage traces from proximal (blue) and distal (red) sites as in $\boldsymbol{A}$. C, Offset between time to half-maximum ( $t_{\text {half }}$ dist $-t_{\text {half }}$ rox) versus distance between recording sites. Red dashed line is linear fit constrained to pass through the origin. 1/slope is indicated as average speed in meters per second as shown. $\boldsymbol{D}$, Average width (left) and WHM (right) of APs recorded from WT (white), overexpression of EKO (red), and WT in the presence of $20 \mu \mathrm{M}$ 4-AP (blue). ${ }^{* *} p<0.01,{ }^{* * *} p<0.001$, Student's $t$ test. $\boldsymbol{E}$, Average peak normalized voltage traces for experiments shown in $\boldsymbol{D}$. External calcium: $\boldsymbol{D}, \boldsymbol{E}, 0.2 \mathrm{~mm}$.

philanthotoxin-433 (Sigma) or $100 \mu \mathrm{M}$ 1-naphthylacetyl spermine (Sigma) was included in the saline to prevent contraction during stimulation. Philanthotoxin had no effect on AP width at $0.4 \mathrm{~mm}$ calcium ( $p=$ 0.93; data not shown).

Data analysis. Imaging data were analyzed using custom-written routines in MATLAB (Mathworks) and digitally filtered at $2 \mathrm{kHz}$. Fluorescence signals consisted of an exponentially decaying signal that derives from tissue fluorescence and is independent of Arch fluorescence, a rapid increase in Arch fluorescence that occurs during the first $10 \mathrm{~ms}$ of the photocycle (Maclaurin et al., 2013), and the voltage-dependent change in Arch fluorescence. To isolate voltage-dependent changes in fluorescence, we fit a single exponential from $10 \mathrm{~ms}$ after the start of imaging to $5 \mathrm{~ms}$ before stimulus onset. This fit, which approximates the tissue fluorescence and the baseline Arch fluorescence, was extrapolated and subtracted from the fluorescence. Traces containing extra APs were removed. The resulting fluorescence measurements were averaged for each bouton, and the average waveform was used to determine peak amplitude, full width, and width at half-maximum (WHM). To obtain precise width and WHM measurements, we used linear interpolation between data sampling points. Because of the inability to accurately measure baseline Arch fluorescence in the presence of tissue fluorescence and Arch localized to internal membranes, amplitude measurements are not reported. Average AP waveforms for each experimental condition were peak aligned and normalized before averaging. To compute AP propagation speed, average fluorescence traces were upsampled from 4 to 100
$\mathrm{kHz}$ using cubic interpolation. The time delay to half-maximum between the upsampled traces along the branch was used to determine the time of propagation.

EPSPs were analyzed using custom-written routines in MATLAB, and mEPSPs were analyzed using Mini Analysis 6.0.0.7 (Synaptosoft). All results are reported as average \pm SEM. $n$ values are reported within figures and represent recordings from individual boutons for voltage imaging experiments or individual muscles for electrophysiological experiments. Statistical significance was assessed by Student's $t$ test or ANOVA (for multiple comparisons) with post hoc Tukey's test, and significance levels were indicated as follows: ${ }^{\star} p<0.05,{ }^{* *} p<0.01,{ }^{* * *} p<0.001$.

\section{Results}

Synaptic voltage imaging with Arch

To measure the AP waveform at the presynaptic nerve terminal, we engineered flies expressing Arch-GFP under control of the GAL4/UAS expression system (Fig. 1A). Arch-GFP expression was restricted to motor neurons using a motor neuronspecific GAL4 driver (OK371-GAL4). To image voltage, we performed spot confocal measurements (see Materials and Methods) using GFP to localize the spot to individual synaptic boutons (Fig. 1A). Arch was excited using $643 \mathrm{~nm}$ laser light. Arch emission was filtered below $700 \mathrm{~nm}$ and collected at a sampling rate of $4 \mathrm{kHz}$. We observed an initial increase in emitted light indicative of the transition of the rhodopsin from the weakly fluorescent and voltage-insensitive ground state to the voltage-sensitive fluorescent state, as described previously (Maclaurin et al. 2013). This initial increase was followed by an exponential decay in fluorescence that also existed in measurements of non-Arch-expressing muscle membrane (Fig. 1A). We interpret this as bleaching of tissue autofluorescence. Bleaching of tissue autofluorescence recovered rapidly between trials. As described previously, Arch is remarkably photostable (Maclaurin et al., 2013). However, in some experiments, we observed a gradual reduction in the initial increase in fluorescence between imaging repetitions that could be attributed to Arch bleaching or other factors. Trials were removed if a decrease in fluorescence caused a measurable effect on the AP waveform. Two copies of the Arch transgene were necessary to resolve AP waveforms in response to a single stimulus (Fig. 1A). In general, we averaged 20-50 stimulus trials to achieve a clearly resolved AP waveform including a prominent afterhyperpolarization (Fig. 1A, black trace).

Arch functions as a proton pump that serves to hyperpolarize cells during activation by green light (Chow et al., 2010). To determine whether our voltage measurements were influenced by activation of the proton pump, we performed simultaneous voltage imaging and extracellular recordings from synaptic boutons at the NMJ (Fig. $1 B-D$ ). We reasoned that, if spot imaging alters the AP waveform, then this should change neurotransmitter release at boutons distal to the imaging site (Fig. 1B). Focal extra- 
A
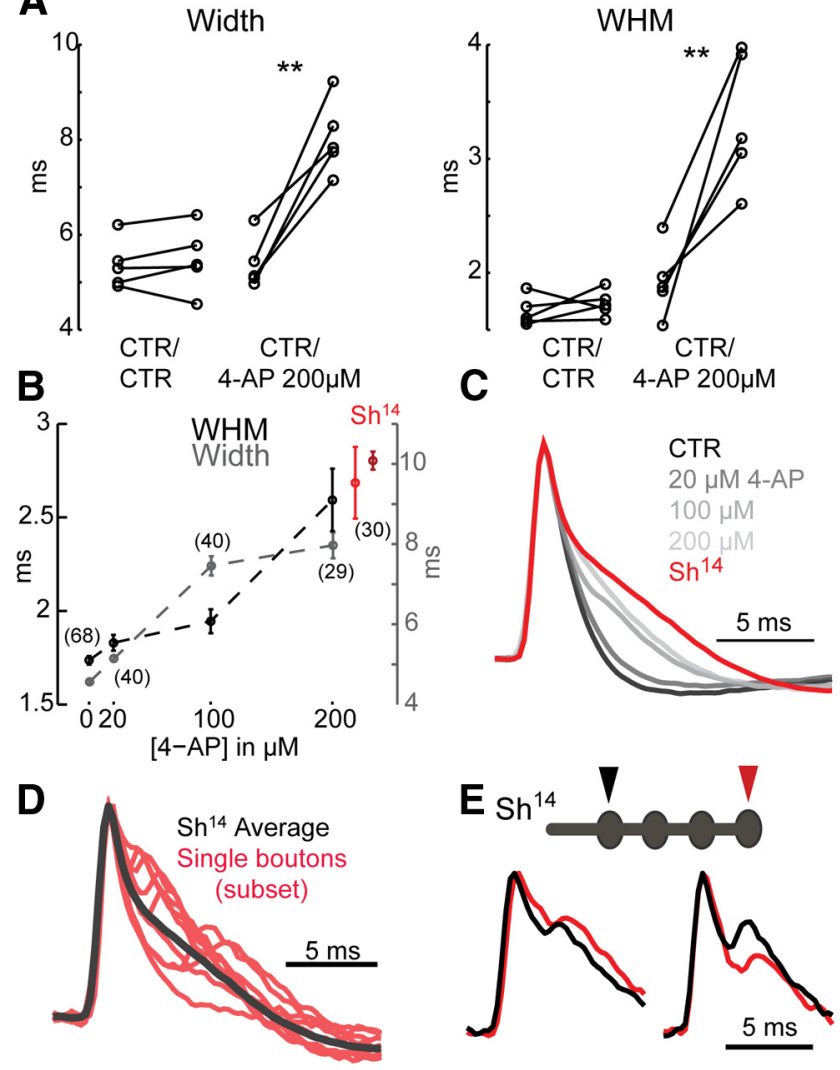

Figure 3. 4-AP-sensitive Shaker channels are necessary for repolarization at low extracellular calcium. $A$, Width (left) and WHM (right) of APs measured from single boutons before and after acute application of saline [control (CTR)] or $200 \mu \mathrm{m} 4-\mathrm{AP} .{ }^{* *} p<0.01$, paired $t$ test. $B$, AP width (gray) and WHM (black) measured in WT at different concentrations of 4-AP. Dotted lines connect WT data. Two points not connected to dotted lines are recordings from $\mathrm{Sh}^{14}$ mutants in the absence of 4-AP (red, width; dark red, WHM). $n$ for each condition is reported in parentheses. C, Average peak normalized AP waveform in WT at 0, 20, 100, and $200 \mu \mathrm{m}$ 4-AP and in $\mathrm{Sh}^{14}$ mutants without 4-AP (red). D, Average peak normalized AP waveform in Sh${ }^{14}$ mutants (black) and a subset of individual boutons (red) displaying spikelets on repolarizing phase. E, Two representative examples of AP waveforms measured from the same synapse at proximal (black) and distal (red) boutons as illustrated in the diagram (top). External calcium: $\boldsymbol{A}-\boldsymbol{D}$, $0.2 \mathrm{~mm} ; \boldsymbol{E}, 0 \mathrm{~mm}$.

cellular recording of synaptic release using a loose-patch technique (Davis and Goodman, 1998) demonstrates that spot illumination does not affect release at distal boutons. Therefore, spot imaging is unlikely to have a strong influence on the AP waveform as it propagates through the nerve terminal (Fig. $1 C, D)$. However, we cannot rule out the possibility of AP regeneration between the site of spot illumination and the distal recording site. To test the sensitivity of this analysis, we excited a large region of nerve terminal proximal to our extracellular recording electrode using $564 \mathrm{~nm}$ light to maximally activate the Arch proton pump. Doing so greatly decreased neurotransmitter release (Fig. 1C,D). Two additional control experiments were performed. First, we demonstrate that larvae expressing Arch develop normally and have wild-type (WT) neurotransmitter release properties (Fig. 1E,F). Second, feeding ATR, which is a necessary cofactor for Arch, to developing larvae did not alter synaptic function (Fig. $1 F$ ). Based on these data, we conclude that Arch excitation at $643 \mathrm{~nm}$ using spot confocal imaging can be used to measure the synaptic AP waveform with minimal interference.

\section{Arch imaging can resolve synaptic AP propagation} and waveform

We first set out to explore the temporal sensitivity of Arch imaging at the Drosophila NMJ. To do so, we sought to determine the propagation speed of the AP through the NMJ using pairs of spot measurements, with each spot being placed along a single branch of the nerve terminal (Fig. $2 \mathrm{~A}$, blue indicates proximal, red indicates distal). We reliably detect a delay in the AP waveform when comparing distal with proximal imaging sites (Fig. $2 B$ ). From these data, we calculate the rate of AP propagation to be $\sim 0.5 \mathrm{~m} / \mathrm{s}$ (Fig. 2C) at room temperature, a value that is similar to that observed in small, unmyelinated vertebrate axons (Debanne et al., 2011).

To further assess the sensitivity of voltage measurements using Arch, we manipulated A-type potassium channel function. It was demonstrated previously that overexpression of a voltageshifted Shaker channel, termed electrical knock-out (EKO; White et al., 2001), is sufficient to cause an $\sim 50 \%$ reduction in neurotransmitter release (Bergquist et al., 2010), implying an effect on the presynaptic AP. Here we show that EKO overexpression decreases AP width by $10.4 \pm 2.4 \%$ and decreases the AP WHM by $11.8 \pm 2.4 \%$ (Fig. $2 \mathrm{D}, E$ ). Conversely, application of $20 \mu \mathrm{M}$ 4 -AP to the Drosophila NMJ causes an $~ 50 \%$ increase in neurotransmitter release (Bergquist et al., 2010), implying AP broadening. Here, we demonstrate that $20 \mu \mathrm{M} 4$-AP causes an increase in AP width of $13.5 \pm 1.5 \%$ and an increase in WHM of $7.6 \pm$ $2.4 \%$ (Fig. $2 D, E$ ). Therefore, voltage imaging with Arch can detect small changes in the AP waveform that correspond to $\sim 50 \%$ changes in neurotransmitter release. Finally, we note that our imaging-based measurement of AP waveform at the presynaptic nerve terminal is nearly identical to somatically recorded AP waveform (Marie et al., 2010; WHM soma, 1.7 ms; WHM terminal, $1.7 \pm 0.02 \mathrm{~ms})$.

\section{Kv1 channels repolarize the AP at low extracellular calcium}

Previous studies investigating the repertoire of channels that function at this nerve terminal have used changes in EPSP waveform to infer effects on the presynaptic AP (Jan and Jan, 1976; Wu et al., 1983; Gho and Ganetzky, 1992). Loss of the Kv1-type potassium channel encoded by Shaker causes a dramatic potentiation of neurotransmitter release and acute channel inhibition with 4-AP mimics the effects of the Shaker mutation (Jan et al., 1977; Ganetzky and Wu, 1982).

We began by reevaluating the effects of the Shaker Kv1-type channel on AP waveform. First, we find that acute application of 4-AP $(200 \mu \mathrm{m})$ enhanced the width and WHM of the presynaptic $\mathrm{AP}$ in saline containing low extracellular calcium (Fig. $3 A$ ). The effect of 4-AP on width and WHM was dose dependent (Fig. $3 \mathrm{~B}, \mathrm{C})$. Second, a functional null mutation in Shaker $\left(\operatorname{Sh}^{14}\right)$ shows a consistent increase in both the width and WHM of the presynaptic AP (Fig. 3 B, C). Therefore, Kv1 channels are necessary for AP repolarization when assessed at the low extracellular calcium concentrations $(0-0.4 \mathrm{~mm})$ used typically to probe neurotransmitter release in this model system (Jan and Jan, 1976; Davis and Goodman, 1998; Frank et al., 2006).

However, when we visualize the repolarizing phase of the AP, the effects of 4-AP and the Shaker mutation are not simply to broaden the AP, as predicted from measurements of neurotransmitter release. Instead, small AP-like depolarizations (termed spikelets) appear during AP repolarization (Fig. 3D). These spikelets generally arise $>500 \mu$ s after AP peak depolarization and occur at variable times during AP repolarization, suggestive of $\mathrm{AP}$ reactivation. In Figure $3 D$, the black trace represents an 
A WT
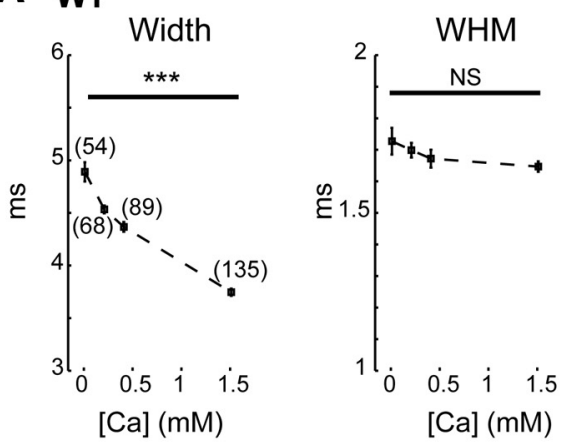

Normalized Avg Trace

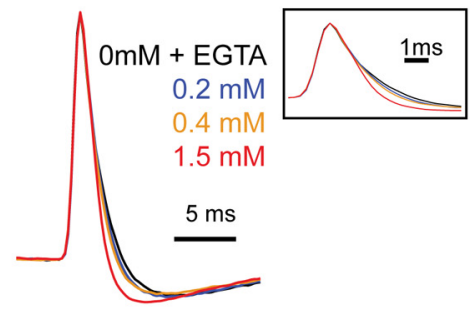

C $1.5 \mathrm{mM} \mathrm{Ca}$

B $\quad 1.5 \mathrm{mM} \mathrm{Ca}$

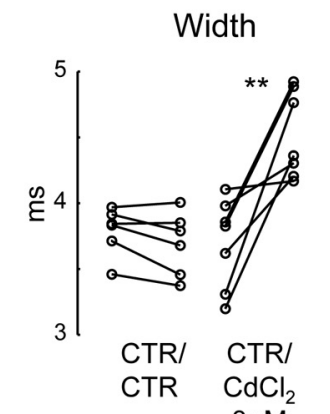

D $\operatorname{sh}^{14} \quad 3 \mu \mathrm{M}^{2}$

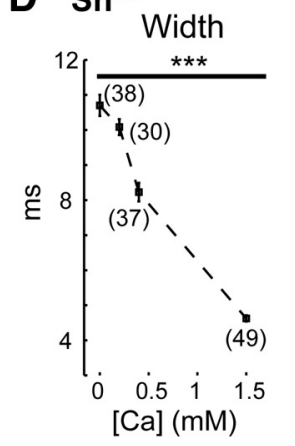

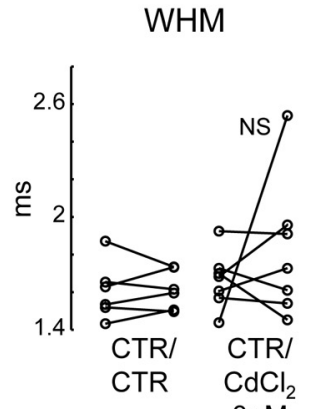

$3 \mu \mathrm{M}$

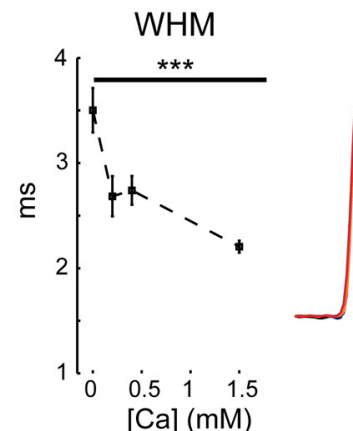

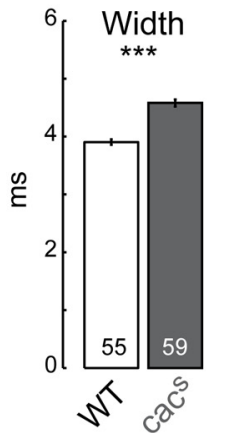

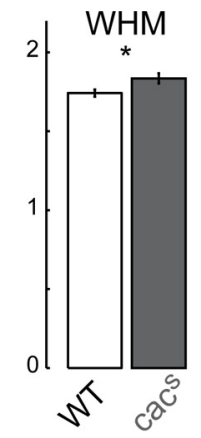

\section{Normalized Avg Trace}

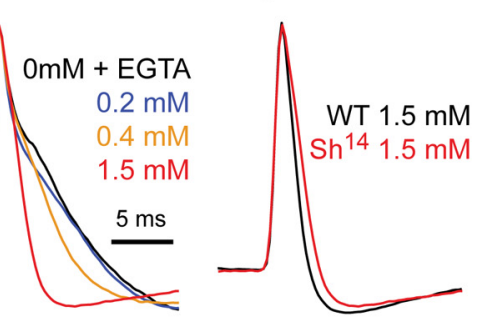

Figure 4. AP width is regulated by calcium influx through voltage-gated calcium channels. $A, A P$ width (left) and WHM (middle) at four different extracellular calcium concentrations $(0,0.2,0.4$, and $1.5 \mathrm{~mm}) .0$ calcium experiments performed in the presence of 1 mм EGTA. Right, Average peak normalized voltage traces for each calcium condition as indicated. Inset shows AP with increased temporal resolution as indicated. ${ }^{* *} p<0.001$, ANOVA with post hoc Tukey's test comparing 0 and 1.5 extracellular calcium conditions. $\boldsymbol{B}$, Width (left) and WHM (right) of APs measured from single boutons before and after application of control (CTR) or saline with $3 \mu \mathrm{m} \mathrm{CdCl}$. Extracellular calcium: $1.5 \mathrm{~mm}$ calcium. ${ }^{* *} p<0.01$, paired $t$ test. NS, Not significant. C, Width (left) and WHM (right) of APs in WT (black) and $c a C^{5}$ (gray). Extracellular calcium: $1.5 \mathrm{~mm} .{ }^{*} p<0.05,{ }^{* * *} p<0.001$, Student's $t$ test. $\boldsymbol{D}$, Experiments as in $A$ using $S h^{14}$ mutants. ${ }^{* * *} p<0.001$, ANOVA with post hoc Tukey's test comparing 0 and 1.5 extracellular calcium conditions. At right, normalized average traces as in $\boldsymbol{A}$.

average waveform measured across multiple synaptic boutons, which acts to smooth the appearance of spikelets that are not temporally synchronized on the falling phase of the AP. This can be contrasted with red traces representing data from individual synaptic boutons. Because recordings are performed in the absence of extracellular calcium, we presume that these recurrent spikelets are sodium based.

Previous work using extracellular recordings from axons of the Shaker mutant have shown evidence of backpropagating APs after a nerve stimulus (Ganetzky and $\mathrm{Wu}, 1982$ ). Therefore, to determine whether the observed spikelets represent APs that "reflect" from the distal end of the nerve terminal back to our site of optical recording, we investigated the relative timing of the spikelets at both proximal and distal locations along single nerve terminals. We found no consistent relationship between the timing

of a spikelet and optical recording position along the nerve terminal. In 4 of 10 recordings, spikelets appear at the proximal location before a distal location and in 2 of 10 recordings appeared at the distal location before the proximal location $(4$ of 10 instances were indeterminate; Fig. $3 E)$. Because we can observe spikelets that appear proximally before distally, it seems unlikely that spikelets originate as a reflection of the AP from the end of the nerve terminal. We speculate that spikelets arise as a result of sodium channel reactivation during the prolonged repolarization phase of the presynaptic AP in a Shaker mutant or after application of 4-AP.

AP width is limited by synaptic calcium Synaptic release machinery is highly sensitive to changes in extracellular calcium (Dodge and Rahamimoff, 1967; Jan and Jan, 1976; Bollmann and Sakmann, 2005). However, little is known about how the $\mathrm{AP}$ at the nerve terminal is modulated by calcium influx. Typical recordings from the Drosophila NMJ are performed in 0.2 $0.5 \mathrm{~mm}$ extracellular calcium versus $\sim 1-3$ $\mathrm{mm}$ extracellular calcium predicted to exist in vivo (Stewart et al., 1994). We find that AP width, but not WHM, is decreased as a function of increasing extracellular calcium (Fig. 4A). To determine whether this effect is attributable to calcium influx through presynaptic voltage-gated calcium channels, we performed both pharmacological and genetic experiments. First, acute application of cadmium (3 $\mu \mathrm{M})$, shown previously to inhibit synaptic transmission mediated by synaptic CaV2.1 channels (Frank et al., 2006), increased AP width without affecting measurements of WHM (Fig. 4B). Next, we asked whether a mutation in the gene encoding the neuronal CaV2.1 channel influences the AP waveform. The CaV2.1 channel encoded by the cacophony (cac) gene is highly concentrated at the active zone and is solely responsible for calcium influx coupled to neurotransmitter release at this synapse (Kawasaki et al., 2004). A point mutation in the Cacophony channel $\left(\mathrm{cac}^{S}\right)$ causes an $\sim 40 \%$ decrease in the spatially averaged presynaptic calcium signal after a single AP (Müller and Davis, 2012). Here we document a significant increase in AP width and a small, statistically significant, increase in WHM in the $\mathrm{cac}^{S}$ mutant background (Fig. 4C). Together, these results demonstrate that calcium influx through presynaptic CaV2.1 channels limits AP waveform. Because we are measuring individual APs, delivered at a low stimulus frequency that should not cause accumulation of intracellular calcium (Müller and Davis, 2012), our data provide evidence that calcium influx occurring during an individual AP acts sufficiently rapidly to speed the repolarization of the same AP. 

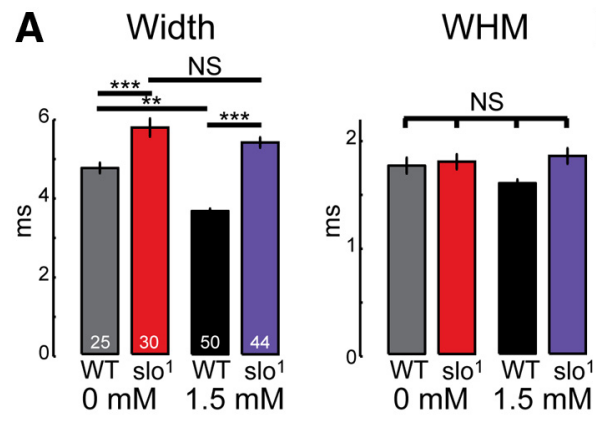

\section{B Normalized Avg Trace}

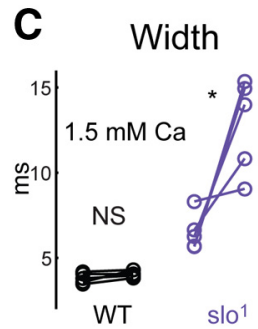

4-AP (-) (+) (-) (+)

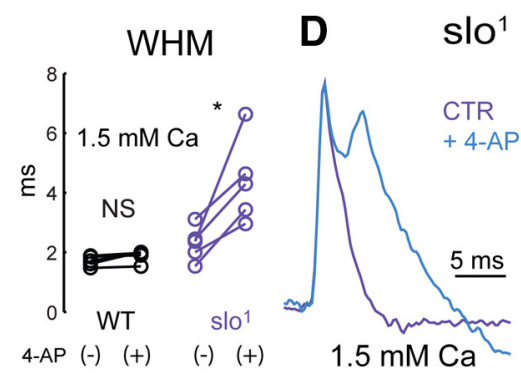

Figure 5. BK channels underlie calcium-dependent change in AP width. $A, A P$ width (left) and WHM (right) in WT and s/0 mutants in $0 \mathrm{~mm}$ calcium plus EGTA and in $1.5 \mathrm{~mm}$ calcium. Two-way ANOVA reveals differences across calcium and genotype for width but not WHM. ${ }^{* *} p<0.01,{ }^{* * *} p<0.001$, ANOVA with post hoc Tukey's test. $\boldsymbol{B}$, Average peak normalized traces for the four genotypes with the extracellular calcium conditions indicated. C, Width (left) and WHM (right) of APs from single boutons measured before and after application of $200 \mu \mathrm{M}$ 4-AP in WT (black) and $s / 0^{1}$ mutants at $1.5 \mathrm{~mm}$ calcium. ${ }^{*} p=0.02$. D, Example AP measured from $s / 0^{7}$ mutant bouton before (purple) and after (blue) application of $200 \mu \mathrm{m}$ 4-AP. CTR, Control.

\section{Calcium-activated BK channels speed AP repolarization}

We next explored how calcium might influence AP repolarization by testing the role of Kv1 and BK channels over a range of extracellular calcium concentrations. First, we examined Shaker mutants at different extracellular calcium concentrations. Surprisingly, AP width and WHM are strongly decreased in the Shaker mutant when extracellular calcium is raised from 0 to 1.5 $\mathrm{mm}$ (physiological) calcium (Fig. 4D). Indeed, at $1.5 \mathrm{~mm}$ extracellular calcium, AP width is similar to WT and does not display any evidence of the spikelets observed when making measurements at lower calcium. From these data, we conclude that the calcium-dependent process that drives AP repolarization does not require Shaker. Furthermore, to our surprise, loss of Shaker has a minimal effect on AP waveform and subsequent neurotransmitter release when recording at physiological calcium (see below for additional details).

We hypothesized that the calcium-dependent influence on AP repolarization is attributable to the action of calcium and voltageactivated BK channels. In Drosophila, BK channels are encoded by the slo gene and have been shown to be both voltage- and calcium-activated potassium channels with fast kinetics (Elkins and Ganetzky, 1988; Sah and Faber, 2002). We imaged the synaptic $\mathrm{AP}$ in $s o^{1}$ mutants at 0 and $1.5 \mathrm{~mm}$ extracellular calcium. In the slo ${ }^{1}$ mutation, APs are wider than WT at both calcium concentrations (Fig. 5A,B). In addition, the calcium-dependent modulation of AP width is absent in $\operatorname{slo}^{1}$ (Fig. $5 A, B$ ). These data suggest that BK channels underlie the calcium-dependent narrowing of AP repolarization observed at this synapse. We note that AP width is wider than WT at 0 extracellular calcium. The slo ${ }^{1}$ mutation is considered a functional null based on the absence of BK current in slo mutant muscle (Singh and Wu, 1990). One pos- sibility is that the slo channels have an activity that is independent of calcium influx.

We further examined conditions that cause spikelets to occur on the AP falling phase. Because the spikelets that are observed when imaging Shaker mutants at low extracellular calcium are suppressed as extracellular calcium is elevated, it suggests that BK channels suppress spikelets in the Shaker mutant background. If so, acute pharmacological inhibition of Kv1 channels in a slo mutant at physiological calcium $(1.5 \mathrm{~mm})$ should phenocopy the appearance of spikelets observed in Shaker mutants at 0 calcium. This is what we observe (Fig. 5C,D). Note that application of 4-AP to WT synapses at physiological calcium did not have a significant effect on AP waveform (Fig. 5C).

Together, our data indicate that Kv1 and BK channels both participate in AP repolarization, and the role of BK channels is strongly influenced by synaptic calcium. In addition, we conclude that, when recordings are made at low extracellular calcium concentrations, the dramatic enhancement of AP width, the appearance of recurrent spikelets on the repolarizing phase of the $\mathrm{AP}$, and the observed potentiation of neurotransmitter release are caused by the absence of both Slo and Shaker activity. Finally, because the recurrent spikelets observed at low extracellular calcium are suppressed as extracellular calcium is elevated, we conclude that the calcium-dependent recruitment of slo channels is sufficient to suppress the appearance of these spikelets.

\section{BK channels stabilize AP repolarization and neurotransmitter release during repetitive firing}

Remarkably little is known regarding how neurotransmitter release is affected by the $S h^{14}$ and $s l o^{1}$ mutations at physiological calcium. To address this, we performed voltage-clamp experiments in slo and Shaker mutants to examine the contribution of these channels to neurotransmitter release. We quantified (1) initial excitatory junction current (EJC) amplitude, (2) the paired-pulse ratio, and (3) the extent and dynamics of EJC amplitude modulation during a stimulus train. There is no significant change in any of these parameters when comparing WT and Shaker mutants (Fig. 6C,D). In contrast, in slo mutants, although there is no alteration in the initial EJC amplitude compared with WT (Fig. 6A), the paired-pulse ratio is significantly increased, as is synaptic depression during a stimulus train (Fig. $6 B-D$ ). Thus, it appears that $s l^{1}$ mutations have a greater effect on neurotransmission at physiological calcium compared with Shaker mutations. Based on this, we sought to determine whether this effect is directly related to altered AP waveform during a stimulus train.

When we image AP waveforms during a stimulus train at physiological calcium, we find a slight, significant increase in width and WHM during repetitive stimulation in WT animals (Fig. 7A-C). Next, we find that Shaker mutants have slightly longer AP width and WHM compared with WT on the first stimulus of a train, but there is no modulation of these measures during a stimulus train. In contrast, in $s l^{1}$ mutants, we find a dramatic increase in AP width and WHM during a stimulus train (Fig. $7 A-C)$. Remarkably, this effect is observed on the second stimulus of a train, affecting both paired-pulse paradigms and prolonged stimulus trains. Thus, repetitive stimulation reveals very different, activity-dependent actions of the Shaker and slo mutations on AP repolarization. One interpretation is that Shaker channels inactivate during a stimulus train, consistent with previous observations at mossy fiber boutons in mammalian hippocampus (Geiger and Jonas, 2000). This is consistent with the finding that APs in Shaker start wider than WT but do not modulate any further during a train. Finally, the dramatic AP broad- 
A

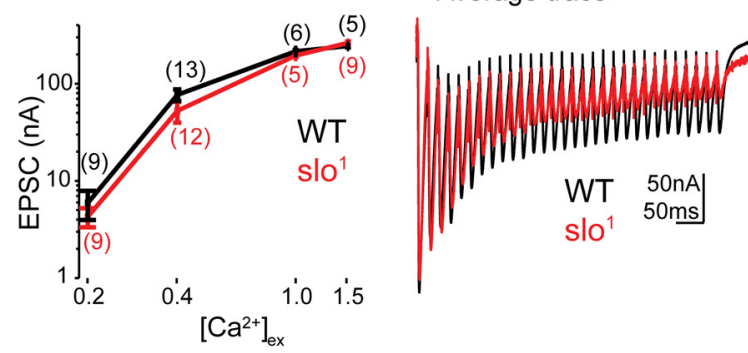

B Average trace

C

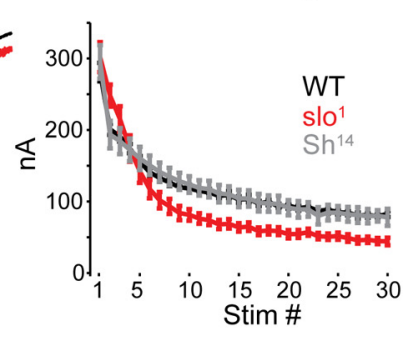

D $\quad$ EPSC 1
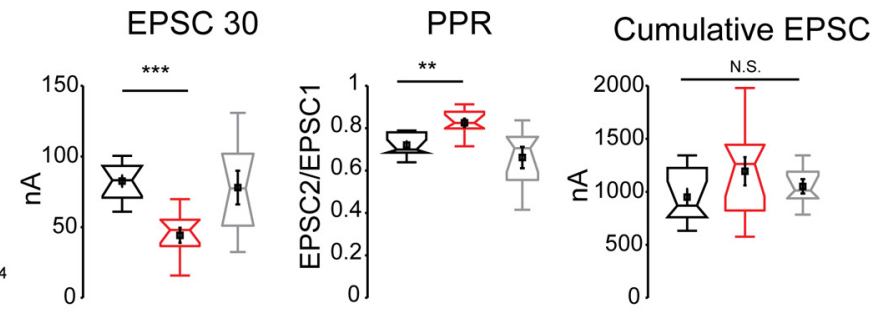

Figure 6. BK channels regulate release during repetitive firing. $A$, Amplitude of EPSCS recorded at four different calcium concentrations in WT (black) and $s / 0^{7}$ (red) mutants. B, Average EPSCs evoked by a $60 \mathrm{~Hz}$ train of 30 stimuli in WT (black) and slo ${ }^{7}$ (red) mutants. C, Summary of EPSC amplitudes during $60 \mathrm{~Hz}$ trains in WT (black), $s / 0^{1}$ (red), and Sh${ }^{14}$ (gray). D, Summary of data from train experiments: first EPSC amplitudes, last EPSC amplitudes, paired-pulse ratio, and cumulative EPSC amplitudes for WT (black), $\mathrm{SlO}^{7}$ (red), and $\mathrm{Sh}^{14}$ (gray). Square with error bars indicate mean and SEM. Box covers 25 th to 75 th quartiles with line at the median and notches to indicate $95 \%$ confidence intervals. Whiskers extend to $1.5 \times(75-25 \%$ quartile), and + indicates outliers. External calcium: $\boldsymbol{B}-\boldsymbol{D}, 1.5 \mathrm{~mm} .{ }^{* *} p<0.01,{ }^{* * *} p<0.001$, ANOVA with post hoc Tukey's test.

A
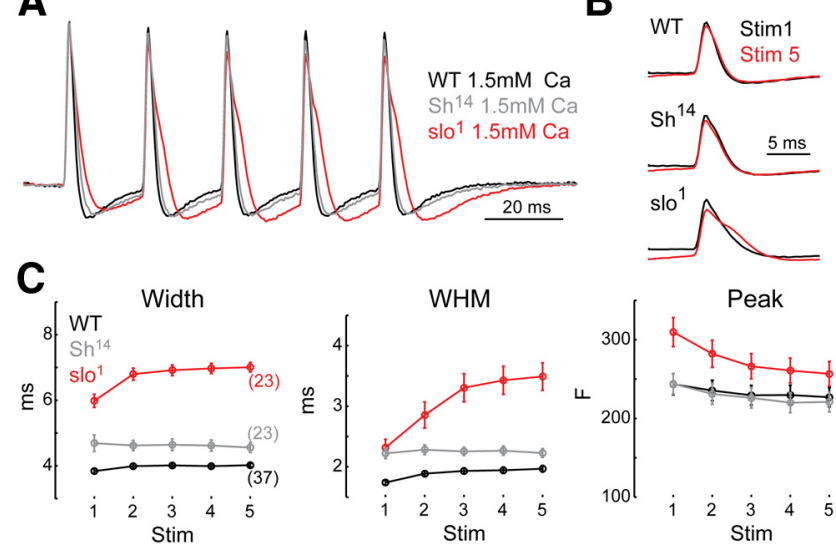

Figure 7. BK channels prevent AP broadening during trains. $A$, Average voltage traces during $50 \mathrm{~Hz}$ trains in $1.5 \mathrm{~mm}$ external calcium for WT (black), $\mathrm{sl}^{1}$ (red), and $\mathrm{Sh}^{14}$ (gray). B, Average voltage traces for first stimulus in train (black) and last stimulus in train (red) for each genotype. Traces are aligned vertically to the baseline before the first AP in the stimulus train and normalized to the first AP peak amplitude. The offset in s/01 is attributable to the presence of enhanced afterhyperpolarization. C, Summary of changes in AP width (left), WHM (middle), and peak (right) in WT (black), slo (red), and $\mathrm{Sh}^{14}$ (gray).

ening observed in the $s o^{1}$ mutant can account for enhanced neurotransmitter release and enhanced depression observed with paired pulses and prolonged stimulus trains (Fig. 6). When taken together, our data demonstrate that Shaker and Slo channels have overlapping activity during AP repolarization in response to a single AP, but Slo plays a dominant repolarizing role during repetitive stimulation that is characteristic of the normal neuromuscular transmission involved in larval locomotion.

\section{Discussion}

Consistent with the original reports of Arch as a transgenically encoded voltage sensor, we find that Arch provides high temporal
EPSCs during train

resolution of the AP waveform in vivo at the Drosophila NMJ. The use of Arch-GFP potentially suffers from low signal-to-noise and the potential for confounding effects of the proton pumping activity of this protein, although new variants of ArchGFP are being pursued (Gong et al., 2013). Here, we circumvented these potential confounds by expressing two copies of the Arch-GFP transgene under UAS control and by performing spot-confocal illumination at $643 \mathrm{~nm}$, a technique that did not induce an interfering activity of the proton pump (Fig. 1).

\section{Evidence for BK channel activation by synaptic calcium influx at the Drosophila NMJ}

In vertebrate systems, BK channels have been characterized somatically (Storm, 1987; Elkins and Ganetzky, 1988; Faber and Sah, 2003) and shown to localize to the nerve terminal in which they concentrate at or near the active zone, assessed by immunolocalization ( $\mathrm{Hu}$ et al., 2001; Misonou et al., 2006) and by detailed patch-clamp electrophysiology (Issa and Hudspeth, 1994; Pattillo et al., 2001; Sun et al., 2004). BK channel activation at elevated membrane voltages (consistent with the rising phase and peak amplitude of an $\mathrm{AP}$ ) is rapid enough that the synaptic BK current closely mirrors the kinetics of an $\mathrm{AP}$ waveform-induced synaptic calcium current (Sun et al., 2004). As such, BK channel function is well suited to shape the AP waveform, responding to the influx of calcium during the same AP.

At the Drosophila NMJ, Slo channels are found at the nerve terminal (Zhou et al., 1999), although it remains unknown precisely where Slo channels localize within the nerve terminal. Furthermore, because neurotransmitter release is normal in the slo mutant (Fig. 6A; Lee et al., 2008), an observation repeated across a range of extracellular calcium concentrations in this study, it has remained unclear whether BK channels have a functional role at the Drosophila NMJ or whether this functional role is masked by homeostatic rebalancing of ion channel expression (Lee et al., 2008). Here, we demonstrate that AP repolarization is influenced by the concentration of extracellular calcium (Fig. 4). This effect is occluded in the slo mutant background indicating that calcium acts on the Slo channel to promote AP repolarization. The source of calcium appears to be synaptically localized Cav2.1 channels (Fig. 4). Together, these data suggest that synaptic calcium influx during an AP activates BK channels and influences AP repolarization at the Drosophila NMJ.

\section{Overlapping activity of KV1 and BK channels ensure robust AP repolarization}

If BK channels, such as slo, participate in AP repolarization, then it is surprising that loss or inhibition of BK channel activity does not alter neurotransmitter release at the Drosophila NMJ or at several other synapses where this has been studied in the vertebrate nervous system (Gho and Ganetzky, 1992; Hu et al., 2001; but see Pattillo et al., 2001; Raffaelli et al., 2004; Lee et al., 2008; Alle et al., 2011). The most prominent effect of BK channel inhibition is observed when it is combined with the application of 
4-AP or, alternatively, when a slo mutation is examined in the presence of a Shaker mutation (Gho and Ganetzky, 1992; Lee et al., 2008). The basis for the synergistic effect of BK and Kv1 channels is essentially unknown.

Here we document a unique phenomenon that allows us to infer the timing of Slo channel activity during AP repolarization. When analyzing AP waveforms in the $S h^{14}$ mutant in the absence of extracellular calcium, we are effectively assaying AP repolarization in the absence of both Shaker and Slo channel activity. In this condition, we observe the presence of resurgent, small APs that we term spikelets, which appear on the fall phase of individual AP waveforms. We presume these spikelets are sodium dependent because they occur in 0 calcium saline, and we rule out the possibility that these are antidromic reflections of the AP within the nerve terminal (Ganetzky and $\mathrm{Wu}, 1982$ ). Importantly, when we raise extracellular calcium, thereby enabling slo channel function in the $S h^{14}$ mutant, these spikelets are abolished. This demonstrates that Slo channels are sufficient to suppress resurgent spikelets in the $S h^{14}$ mutant. Given this finding, we can use the distribution of spikelets on the falling phase of the AP to delineate the window during which Slo channel activity normally participates in AP repolarization. The spikelets appear within $\sim 1$ ms of the AP peak and are observed throughout the falling phase (Fig. 3D). We infer, from these data, that Slo channels, at the Drosophila NMJ, are activated by voltage and calcium near the AP peak and contributed significantly to AP repolarization.

Importantly, the functional relevance of BK channels during AP repolarization in this system could not have been appreciated from a simple comparison of WT and slo mutants. Indeed, quantification of the slo mutant AP demonstrates that there is no change in AP WHM at physiological calcium. In addition, there is no change in neurotransmitter release or the calcium cooperativity of release over a range of extracellular calcium concentrations in the slo mutant (Fig. 6). These data are consistent with previous reports that the loss or block of BK channels does not alter neurotransmitter release in other systems, despite evidence that these channels are present at the nerve terminal (Hu et al., 2001; Alle et al., 2011). Our data are consistent with the conclusion that Slo channels functionally overlap with Shaker channels such that removal of either channel alone does not dramatically disrupt AP repolarization (see below).

Our data also contribute to a better understanding of how Shaker channels participate in AP repolarization and neurotransmitter release. Most importantly, although there is a slight increase the AP WHM in Shaker mutants compared with WT at physiological calcium, this does not translate into enhanced neurotransmitter release (Fig. 6D). This is in stark contrast to the dramatic potentiation of release observed at calcium concentrations used commonly for electrophysiology experiments in the literature $\left(0.2-0.5 \mathrm{mM} \mathrm{Ca}^{2+}\right)$, an effect that we now attribute to the combined absence of both Shaker and Slo activity.

The relationship between loss of Shaker, AP duration, and neurotransmitter release is also dependent on extracellular calcium. We note that a modest broadening of the AP at low extracellular calcium, attributable to application of sub-blocking concentrations of 4-AP $(20-50 \mu \mathrm{M})$, is sufficient to cause a $50 \%$ increase in neurotransmitter release (Fig. 2; Bergquist et al., 2010). In contrast, a similar percentage broadening of the AP at $1.5 \mathrm{~mm}$ extracellular $\mathrm{Ca}^{2+}$ does not significantly potentiate neurotransmitter release (Fig. $6 D$ ). We attribute this difference to the highly nonlinear relationship between calcium influx and release. At low extracellular calcium concentrations $(0.2-0.6 \mathrm{~mm})$, release is steeply calcium dependent, conforming to a power func- tion with an exponent of 3-4. The calcium-release relationship becomes nearly linear at extracellular calcium concentrations $\geq 1$ mM (Müller et al., 2012), explaining why the modest AP broadening at elevated external calcium in $S h^{14}$ mutants may have less effect on release.

Based on our data, we propose that Shaker channels are sufficient to drive the early repolarization of the AP in the absence of BK channel activity, masking an important role of BK channels during this early repolarization phase. An analysis of stimulus trains underscores why it is essential to have overlapping Shaker and BK channel function. It has been demonstrated in both mossy fiber boutons and boutons of cortical pyramidal neurons that Kv1 channels inactivate during a stimulus train (Geiger and Jonas, 2000; Foust et al., 2011). Our data suggest a similar effect at the Drosophila NMJ. In WT, we observe a slight AP broadening during a stimulus train. AP broadening is unaffected in $S h^{14}$. However, AP broadening during a train is dramatically enhanced in a $s l^{1}$ mutant background, with spikelets appearing on the AP falling phase (Fig. $7 B$ ), consistent with our observations of AP repolarization in conditions that lack both Shaker and Slo activity. During a stimulus train in the slo mutant, both AP width and WHM increase (Fig. 7C), and these changes are associated with significant potentiation of presynaptic neurotransmitter release (Fig. 6D). This effect is already prominent on the second AP of a stimulus train and occurs at a stimulus frequency that is consistent with normal neuromuscular function in vivo (Kurdyak et al., 1994; Schaefer et al., 2010). From these data, we conclude that the overlapping activity of BK and Kv1 channels is essential to stabilize AP repolarization attributable to prominent Shaker channel inactivation during repetitive firing. These data also provide an explanation for the synthetic genetic interaction of Shaker and slo mutations (Lee et al., 2008) and the synergistic effect of 4-AP and $\mathrm{BK}$ channel inhibitors at mammalian central synapses ( $\mathrm{Hu}$ et al., 2001).

\section{References}

Alle H, Kubota H, Geiger JR (2011) Sparse but highly efficient Kv3 outpace BKCa channels in action potential repolarization at hippocampal mossy fiber boutons. J Neurosci 31:8001-8012. CrossRef Medline

Bergquist S, Dickman DK, Davis GW (2010) A hierarchy of cell intrinsic and target-derived homeostatic signaling. Neuron 66:220-234. CrossRef Medline

Bollmann JH, Sakmann B (2005) Control of synaptic strength and timing by the release-site Ca2 + signal. Nat Neurosci 8:426-434. CrossRef Medline

Buckle PJ, Haas HL (1982) Enhancement of synaptic transmission by 4-aminopyridine in hippocampal slices of the rat. J Physiol 326:109-122. Medline

Chow BY, Han X, Dobry AS, Qian X, Chuong AS, Li M, Henninger MA, Belfort GM, Lin Y, Monahan PE, Boyden ES (2010) High-performance genetically targetable optical neural silencing by light-driven proton pumps. Nature 463:98-102. CrossRef Medline

Collins CA, DiAntonio A (2007) Synaptic development: insights from Drosophila. Curr Opin Neurobiol 17:35-42. CrossRef Medline

Davis GW (2013) Homeostatic signaling and the stabilization of neural function. Neuron 80:718-728. CrossRef Medline

Davis GW, Goodman CS (1998) Synapse-specific control of synaptic efficacy at the terminals of a single neuron. Nature 392:82-86. CrossRef Medline

Debanne D, Campanac E, Bialowas A, Carlier E, Alcaraz G (2011) Axon physiology. Physiol Rev 91:555-602. CrossRef Medline

Dodge FA Jr, Rahamimoff R (1967) Co-operative action a calcium ions in transmitter release at the neuromuscular junction. J Physiol 193:419432. Medline

Dodson PD, Billups B, Rusznák Z, Szûcs G, Barker MC, Forsythe ID (2003) Presynaptic rat Kv1.2 channels suppress synaptic terminal hyperexcitability following action potential invasion. J Physiol 550:27-33. CrossRef Medline 
Elkins T, Ganetzky B (1988) The roles of potassium currents in Drosophila flight muscles. J Neurosci 8:428-434. Medline

Faber ES, Sah P (2003) Ca2 +-activated K+ (BK) channel inactivation contributes to spike broadening during repetitive firing in the rat lateral amygdala. J Physiol 552:483-497. CrossRef Medline

Foust AJ, Yu Y, Popovic M, Zecevic D, McCormick DA (2011) Somatic membrane potential and Kvl channels control spike repolarization in cortical axon collaterals and presynaptic boutons. J Neurosci 31:1549015498. CrossRef Medline

Frank CA, Kennedy MJ, Goold CP, Marek KW, Davis GW (2006) Mechanisms underlying the rapid induction and sustained expression of synaptic homeostasis. Neuron 52:663-677. CrossRef Medline

Ganetzky B, Wu CF (1982) Drosophila mutants with opposing effects on nerve excitability: genetic and spatial interactions in repetitive firing. J Neurophysiol 47:501-514. Medline

Geiger JR, Jonas P (2000) Dynamic control of presynaptic Ca(2+) inflow by fast-inactivating $\mathrm{K}(+)$ channels in hippocampal mossy fiber boutons. Neuron 28:927-939. CrossRef Medline

Gho M, Ganetzky B (1992) Analysis of repolarization of presynaptic motor terminals in Drosophila larvae using potassium-channel-blocking drugs and mutations. J Exp Biol 170:93-111. Medline

Gong Y, Li JZ, Schnitzer MJ (2013) Enhanced Archaerhodopsin fluorescent protein voltage indicators. PLoS One 8:e66959. CrossRef Medline

Hu H, Shao LR, Chavoshy S, Gu N, Trieb M, Behrens R, Laake P, Pongs O, Knaus HG, Ottersen OP, Storm JF (2001) Presynaptic Ca2+-activated $\mathrm{K}+$ channels in glutamatergic hippocampal terminals and their role in spike repolarization and regulation of transmitter release. J Neurosci 21: 9585-9597. Medline

Issa NP, Hudspeth AJ (1994) Clustering of Ca2+ channels and $\mathrm{Ca}(2+)$ activated $\mathrm{K}+$ channels at fluorescently labeled presynaptic active zones of hair cells. Proc Natl Acad Sci U S A 91:7578-7582. CrossRef Medline

Jan LY, Jan YN (1976) Properties of the larval neuromuscular junction in Drosophila melanogaster. J Physiol 262:189-214. Medline

Jan YN, Jan LY, Dennis MJ (1977) Two mutations of synaptic transmission in Drosophila. Proc R Soc Lond B Biol Sci 198:87-108. CrossRef Medline

Kawasaki F, Zou B, Xu X, Ordway RW (2004) Active zone localization of presynaptic calcium channels encoded by the cacophony locus of Drosophila. J Neurosci 24:282-285. CrossRef Medline

Knaus HG, Schwarzer C, Koch RO, Eberhart A, Kaczorowski GJ, Glossmann H, Wunder F, Pongs O, Garcia ML, Sperk G (1996) Distribution of high-conductance $\mathrm{Ca}(2+)$-activated $\mathrm{K}+$ channels in rat brain: targeting to axons and nerve terminals. J Neurosci 16:955-963. Medline

Kralj JM, Douglass AD, Hochbaum DR, Maclaurin D, Cohen AE (2012) Optical recording of action potentials in mammalian neurons using a microbial rhodopsin. Nat Methods 9:90-95. CrossRef Medline

Kurdyak P, Atwood HL, Stewart BA, Wu CF (1994) Differential physiology and morphology of motor axons to ventral longitudinal muscles in larval Drosophila. J Comp Neurol 350:463-472. CrossRef Medline

Lee J, Ueda A, Wu CF (2008) Pre- and post-synaptic mechanisms of synaptic strength homeostasis revealed by slowpoke and shaker $\mathrm{K}+$ channel mutations in Drosophila. Neuroscience 154:1283-1296. CrossRef Medline

Lee J, Ueda A, Wu CF (2014) Distinct roles of Drosophila cacophony and Dmca1D $\mathrm{Ca}(2+)$ channels in synaptic homeostasis: genetic interactions with slowpoke $\mathrm{Ca}(2+)$-activated $\mathrm{BK}$ channels in presynaptic excitability and postsynaptic response. Dev Neurobiol 74:1-15. CrossRef Medline

Maclaurin D, Venkatachalam V, Lee H, Cohen AE (2013) Mechanism of voltage-sensitive fluorescence in a microbial rhodopsin. Proc Natl Acad Sci U S A 110:5939-5944. CrossRef Medline

Mallart A, Angaut-Petit D, Bourret-Poulain C, Ferrús A (1991) Nerve terminal excitability and neuromuscular transmission in $\mathrm{T}(\mathrm{X} ; \mathrm{Y}) \mathrm{V} 7$ and Shaker mutants of Drosophila melanogaster. J Neurogenet 7:75-84. CrossRef Medline

Marie B, Pym E, Bergquist S, Davis GW (2010) Synaptic homeostasis is consolidated by the cell fate gene gooseberry, a Drosophila pax3/7 homolog. J Neurosci 30:8071-8082. CrossRef Medline

Martínez-Padrón M, Ferrús A (1997) Presynaptic recordings from Drosophila: correlation of macroscopic and single-channel $\mathrm{K}+$ currents. J Neurosci 17:3412-3424. Medline
Misonou H, Menegola M, Buchwalder L, Park EW, Meredith A, Rhodes KJ, Aldrich RW, Trimmer JS (2006) Immunolocalization of the Ca2+activated $\mathrm{K}+$ channel Slo1 in axons and nerve terminals of mammalian brain and cultured neurons. J Comp Neurol 496:289-302. CrossRef Medline

Müller M, Davis GW (2012) Transsynaptic control of presynaptic Ca(2)(+) influx achieves homeostatic potentiation of neurotransmitter release. Curr Biol 22:1102-1108. CrossRef Medline

Müller M, Liu KS, Sigrist SJ, Davis GW (2012) RIM controls homeostatic plasticity through modulation of the readily-releasable vesicle pool. J Neurosci 32:16574-16585. CrossRef Medline

Nakamura Y, Takahashi T (2007) Developmental changes in potassium currents at the rat calyx of Held presynaptic terminal. J Physiol 581:11011112. CrossRef Medline

Pattillo JM, Yazejian B, DiGregorio DA, Vergara JL, Grinnell AD, Meriney SD (2001) Contribution of presynaptic calcium-activated potassium currents to transmitter release regulation in cultured Xenopus nerve-muscle synapses. Neuroscience 102:229-240. CrossRef Medline

Raffaelli G, Saviane C, Mohajerani MH, Pedarzani P, Cherubini E (2004) BK potassium channels control transmitter release at CA3-CA3 synapses in the rat hippocampus. J Physiol 557:147-157. CrossRef Medline

Robitaille R, Charlton MP (1992) Presynaptic calcium signals and transmitter release are modulated by calcium-activated potassium channels. J Neurosci 12:297-305. Medline

Rowan MJM, Tranquil E, Christie JM (2014) Distinct Kv channel subtypes contribute to differences in spike signaling properties in the axon initial segment and presynaptic boutons of cerebellar interneurons. J Neurosci 34:6611-6623. CrossRef Medline

Sah P, Faber ES (2002) Channels underlying neuronal calcium-activated potassium currents. Prog Neurobiol 66:345-353. CrossRef Medline

Schaefer JE, Worrell JW, Levine RB (2010) Role of intrinsic properties in Drosophila motoneuron recruitment during fictive crawling. J Neurophysiol 104:1257-1266. CrossRef Medline

Singh S, Wu CF (1990) Properties of potassium currents and their role in membrane excitability in Drosophila larval muscle fibers. J Exp Biol 152: 59-76. Medline

Stern M, Ganetzky B (1989) Altered synaptic transmission in Drosophila hyperkinetic mutants. J Neurogenet 5:215-228. CrossRef Medline

Stewart BA, Atwood HL, Renger JJ, Wang J, Wu CF (1994) Improved stability of Drosophila larval neuromuscular preparations in haemolymphlike physiological solutions. J Comp Physiol A 175:179-191. CrossRef Medline

Storm JF (1987) Action potential repolarization and a fast afterhyperpolarization in rat hippocampal pyramidal cells. J Physiol 385:733759. Medline

Sun XP, Yazejian B, Grinnell AD (2004) Electrophysiological properties of BK channels in Xenopus motor nerve terminals. J Physiol 557:207-228. CrossRef Medline

Ueda A, Wu CF (2006) Distinct frequency-dependent regulation of nerve terminal excitability and synaptic transmission by IA and IK potassium channels revealed by Drosophila Shaker and Shab mutations. J Neurosci 26:6238-6248. CrossRef Medline

Warbington L, Hillman T, Adams C, Stern M (1996) Reduced transmitter release conferred by mutations in the slowpoke-encoded $\mathrm{Ca} 2(+)-$ activated $\mathrm{K}+$ channel gene of Drosophila. Invert Neurosci 2:51-60. CrossRef Medline

White BH, Osterwalder TP, Yoon KS, Joiner WJ, Whim MD, Kaczmarek LK, Keshishian H (2001) Targeted attenuation of electrical activity in Drosophila using a genetically modified $\mathrm{K}(+)$ channel. Neuron 31:699-711. CrossRef Medline

Wu CF, Ganetzky B, Haugland FN, Liu AX (1983) Potassium currents in Drosophila: different components affected by mutations of two genes. Science 220:1076-1078. CrossRef Medline

Zhou Y, Schopperle WM, Murrey H, Jaramillo A, Dagan D, Griffith LC, Levitan IB (1999) A dynamically regulated 14-3-3, Slob, and Slowpoke potassium channel complex in Drosophila presynaptic nerve terminals. Neuron 22:809-818. CrossRef Medline 